\title{
Bentonite from Porto Santo Island, Madeira archipelago: surface properties studied by inverse gas chromatography
}

\author{
N. CORDEIRO ${ }^{1, *}$, J. SILVA $^{2}$, C. GOMES ${ }^{2}$ AND F. ROCHA ${ }^{2}$ \\ ${ }^{1}$ CEM, Research Centre of Macaronesia Studies of the Foundation for Science and Technology (FCT), and \\ Chemistry Department, University of Madeira, 9000-390 Funchal, Portugal, and ${ }^{2}$ GeoBioTec, Research Centre of the \\ Foundation for Science and Technology (FCT), Geosciences Department, University of Aveiro, 3810-193 Aveiro, \\ Portugal
}

(Received 20 March 2009; revised 8 December 2009; Editor: John Adams)

\begin{abstract}
The present paper shows the importance of Inverse Gas Chromatography (IGC) for the determination of the surface properties of bentonites. These properties are dispersive surface energy, acid-base properties, surface heterogeneity, sorption isotherms, BET surface areas and heat of sorption, using different probe molecules. IGC can contribute to the interpretation, prediction and optimization of the studied materials' properties. The paper focuses on two distinctive bentonite samples from Porto Santo Island, Madeira archipelago. In view of their potential value, achieved through their incorporation in products for dermopharmacy and dermocosmetics, particle size and particle surface properties are of fundamental importance.
\end{abstract}

KEYWORDS: inverse gas chromatography, bentonite, particle size and surfaces, surface properties, dermopharmacy, dermocosmetics.

Bentonite occurs in several outcrops in Porto Santo Island, Madeira archipelago, and is characterized by deposits of small size. These are impracticable for commercial exploitation for the common uses of bentonite: filtering, decolourizing and clarifying, pelletizing, animal feed, pet litter absorbent and waste disposal liners. Nevertheless, for applications requiring small volumes of material, such as pharmaceutical and cosmetic products, use of these deposits could be feasible (Gomes, 2005; Gomes \& Silva, 2007). These applications utilize specific characteristics of the clay, such as mineralogical composition (clay minerals and nonclay mineral typology and content), chemical composition (major, minor and trace elements),

\footnotetext{
* E-mail: ncordeiro@uma.pt
}

DOI: $10.1180 /$ claymin.2010.045.1.77 mean grain size and grain-size distribution, particle shape, specific surface area, cation-exchange capacity, sorption and adsorption capacities, expansibility, plasticity, abrasiveness, specific heat and heat diffusiveness and attenuation (Gomes \& Silva, 2001; Silva, 2003; Gomes \& Silva, 2006a,b).

In the present work, two specimens of bentonite were analysed by Inverse Gas Chromatography (IGC) in order to obtain information on their surface properties. Traditionally, surface energies are measured by liquid wetting techniques. However, these methods are difficult to replicate on powdered materials, since they usually involve a compression of the powder, which can change its surface characteristics. Moreover, only a limited number of probe molecules can be used for the wettability method; for instance, in materials with relatively large surface energies, many of the potentially interesting probe molecules spread across the surface, preventing its use. Another 
problem with wettability methods is the absorption of liquid in the bulk clay which leads to an overestimation of the surface energy. These problems can be eliminated using IGC, which is a dynamic technique involving injection of a known amount of individual sorbate (n-alkanes and polar components) into a column packed with the material to be tested and placed in an oven. The retention time can be converted into a retention volume, which is directly related to various physicochemical properties such as the surface energy or heat of sorption as examples of thermodynamic properties, or kinetic parameters such as the diffusion and the activation energy of diffusion. Another possibility is the determination of the uptake both for physisorption and chemisorption. The flexibility of the IGC method makes it a useful tool in the characterization of various materials. For example, it has been successfully applied in batch-to-batch studies involving synthetic or biological materials, copolymers, polymer blends, adsorbents (Xie et al., 1998, ElizaldeGonzález \& Ruíz-Palma, 1999), foods (Boutboul et al., 2002), carbon blacks (Papirer et al., 1999) and fibres (Vega et al., 2002). These applications demonstrate the usefulness of IGC for the investigation of the surface energies of a wide range of minerals. Saada et al. (1995) studied the surface properties of illites from various sources in order to characterize the surface morphology. Price \& Ansari (2003) used the method to study the effect of firing in the modification of kaolinite surfaces. Other studies were carried out in order to determine the effects of the chemical modification in clays (Bandosz et al., 1992).

In the current work, surface properties of Porto Santo bentonites were determined by IGC. Experiments were carried out at different temperatures to measure the enthalpies and free energies of sorption, and with increasing amounts of n-alkanes to determine the sorption isotherms and the solubility coefficients. Permeability studies were carried out under increasing gas flow. Humidity studies were carried out in order to determine the influence on the surface properties of bentonite.

\section{MATERIALS AND METHODS}

\section{Materials}

The two specimens of bentonite were collected at two occurrences: one in Serra de Dentro (BSD) displayed a greenish-yellowish colour, the source rock being a pyroclastic volcanic rock of trachyte composition; the other from Fonte da Areia (BFA) displayed a greyish-greenish colour, the source rock being a porphyritic trachyrhyolite flow. In both cases the alteration process would have taken place essentially in a submarine environment, the formation of the Serra de Dentro bentonite being much older (Miocene) than the Fonte da Areia bentonite (Pleistocene).

Wet sieving allowed the separation of two size fractions from bentonite BSD: one having an equivalent spherical diameter (e.s.d.) $<0.063 \mathrm{~mm}$ (BSDL63); other having an e.s.d $>0.063 \mathrm{~mm}$ (BSDH63).

In terms of mineralogical composition, the $<0.063 \mathrm{~mm}$ size fraction of BSD is composed of dioctahedral smectite, Na-Ca feldspar, Na-pyroxene, titanomagnetite and fluorapatite. The chemical composition of this size fraction is: $\mathrm{SiO}_{2}$ (45.01 wt.\%); $\quad \mathrm{Al}_{2} \mathrm{O}_{3}$ (18.57 wt.\%); $\quad \mathrm{Fe}_{2} \mathrm{O}_{3}$ (10.85 wt.\%); $\mathrm{TiO}_{2} \quad(2.77$ wt. \%); $\mathrm{MnO}$ (0.86 wt.\%); $\mathrm{MgO}$ (3.86 wt.\%); $\mathrm{CaO}$ (5.97 wt.\%); $\mathrm{Na}_{2} \mathrm{O}$ (2.37 wt.\%); $\mathrm{K}_{2} \mathrm{O} \quad(0.45$ wt. $\%) ; \mathrm{P}_{2} \mathrm{O}_{5}$ (1.76 wt.\%); and I.L.(7.54 wt.\%). Other studies provided the following results: specific surface area $\left(119 \mathrm{~m}^{2} \mathrm{~g}^{-1}\right)$, cation exchange capacity $\left(80 \mathrm{cmol} \mathrm{kg}^{-1}\right)$; particle-size distribution $(90 \%$ of particles have an e.s.d. $<0.010 \mathrm{~mm}, 71 \%$ $<0.002 \mathrm{~mm}$ ). Local people have used this clay for cosmetic applications, particularly in the form of facial masks (Silva, 2003).

The $<0.063 \mathrm{~mm}$ size fraction of $\mathrm{BFA}$ is composed of dioctahedral smectite, structurally disordered dioctahedral illite, kaolinite, quartz, $\mathrm{K}$-feldspar, Na-Ca-feldspar, goethite and todorokite. Its chemical composition is: $\mathrm{SiO}_{2}$ (53.64 wt.\%); $\mathrm{Al}_{2} \mathrm{O}_{3} \quad$ (16.20 wt.\%); $\quad \mathrm{Fe}_{2} \mathrm{O}_{3} \quad$ (13.45 wt.\%); $\mathrm{TiO}_{2}$ (2.30 wt.\%); $\mathrm{MnO}$ (0.18 wt.\%); $\mathrm{MgO}$ (1.96 wt.\%); $\mathrm{CaO}$ (1.05 wt.\%); $\mathrm{Na}_{2} \mathrm{O}$ (1.94 wt.\%); $\mathrm{K}_{2} \mathrm{O}$ (4.24 wt.\%); $\mathrm{P}_{2} \mathrm{O}_{5}$ (0.45 wt.\%); $\mathrm{SO}_{3}$ (0.06 wt.\%); I.L.(5.10 wt.\%); Cr (0.02 wt.\%); Zn (0.09 wt.\%); $\mathrm{Sr}$ (0.4 wt.\%); V (0.18 wt.\%); Co (0.03 wt.\%); Ni (0.04 wt.\%); Cu (0.02 wt.\%); As (0.008 wt.\%); Ba (0.13 wt.\%); and $\mathrm{Ce}(0.05$ wt.\%). Other characteristics were studied, namely: specific surface area $\left(70 \mathrm{~m}^{2} \mathrm{~g}^{-1}\right)$; cation exchange capacity $\left(55 \mathrm{cmol} \mathrm{kg}^{-1}\right)$; particle-size distribution $(60 \%$ of particles have an e.s.d. $<0.010 \mathrm{~mm}$ and $30 \%$ $<0.002 \mathrm{~mm})$.

The IGC measurements were carried out on these samples using several probe molecules, all GC 
grade ( $>99 \%$ purity) supplied by Sigma-Aldrich. The apolar probes used were: n-hexane, n-heptane, n-octane, n-nonane, n-decane and cyclohexane. Acetone, dichloromethane, chloroform, benzene and methanol were used as polar probes. Methane ( $>99.99 \%$ purity) was used as a non-interacting reference probe, and the carrier gas utilized was $\mathrm{He}$ ( $>99.99 \%$ purity) supplied by the Air Liquide Company.

\section{IGC analysis}

The IGC measurements were carried out using a commercial inverse gas chromatograph (Surface Measurements Systems, London, UK) equipped with flame ionization (FID) and thermal conductivity (TCD) detectors. Standard glass silanized (dimethyldichlorosilane; Repelcote BDH, UK) columns with $0.2 \mathrm{~cm}$ internal diameter and 30 long were used. About $100 \mathrm{mg}$ of the bentonite powders were packed by vertical tapping for $5 \mathrm{~min}$. The columns with the samples were pre-treated for $2 \mathrm{~h}$ at $393 \mathrm{~K}$ and $10 \mathrm{ml} \mathrm{min}^{-1}$ flow rate to remove impurities adsorbed on the surface, and $2 \mathrm{~h}$ at the measurement conditions. After pre-treatment, pulse injections were carried out with a $0.25 \mathrm{ml}$ gas loop. Measurements of the dispersive interaction were made with n-alkanes (decane, nonane, octane, heptane and hexane) at 363 and $393 \mathrm{~K}$ and at $0 \%$ R.H. To study the influence of humidity, dispersive interaction studies at $303 \mathrm{~K}$ and 10, 20 and $30 \%$ R.H. were carried out. The carrier gas (He) flow rate was $10 \mathrm{ml}$ $\min ^{-1}$. Acid-base studies were carried out using acetone, dichloromethane, chloroform, benzene and methanol, at $0 \%$ R.H. Isotherm experiment measurements were undertaken with hexane at $0.2,0.3,0.4$, $0.5,0.6,0.7$ and $0.95 p / p_{0}, 303 \mathrm{~K}$ and flow rate at

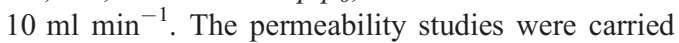
out with n-hexane at $303 \mathrm{~K}$ and flow rate of 7,10 , $13,16,19,22,25$ and $28 \mathrm{ml} \mathrm{min}^{-1}$. Heat of sorption measurements were carried out with n-heptane at 373, 383, 388 and 393 K, 0\% R.H., and $10 \mathrm{ml} \mathrm{min}{ }^{-1}$ flow rate. The humidity influence (10\% R.H.) was investigated at 298, 313 and $318 \mathrm{~K}$.

The IGC system was fully automatic with SMS $i$ GC Controller v1.3 control software, and the data obtained were analysed using the $i \mathrm{GC}$ Standard v1.3 and Advanced Analysis Software v1.21. The results presented correspond to the average of the values obtained, which were obtained at least in duplicate for each bentonite specimen with a standard deviation $<5 \%$.

\section{RESULTS AND DISCUSSION}

\section{Dispersive component of the surface tension}

The solvent-sorption properties of the bentonite specimens were investigated at infinite dilution conditions in order to eliminate interactions with the probe molecules adsorbed at the surface of the samples. Methane injection permits the calculation of the dead time and subtracts it from the retention time in order to obtain the retention volume (Conder \& Young, 1979; Lloyd et al., 1989). The corrected net retention volume $V_{\mathrm{N}}$ is given by equation 1 :

$$
V_{\mathrm{N}}=V_{\mathrm{R}}^{0}-V_{\mathrm{d}}^{0}
$$

where $V_{\mathrm{d}}$ is the mobile phase hold-up volume (called dead volume), and $V_{\mathrm{R}}$ is the measured retention volume (equation 2). The 0 superscript indicates a correction for the column pressure drop given by $j$ (equation 3)

$$
\begin{aligned}
& V_{\mathrm{R}}^{0}=\frac{j}{m} F t_{\mathrm{R}} \frac{T}{273.15} \\
& j=\frac{3}{2}\left[\frac{\left(\frac{P_{i}}{P_{0}}\right)^{2}-1}{\left(\frac{P_{i}}{P_{0}}\right)^{3}-1}\right]
\end{aligned}
$$

$T$ is the column temperature, $F$ is the exit flow rate at $1 \mathrm{~atm}$ and $273.15 \mathrm{~K}$, and $t_{R}$ is the retention time.

The dispersive component of the surface energy, as well as the specific free energy of sorption, was measured with dispersive and acid-base probe molecules. The relation between the retention volume and free energy of sorption $\Delta G_{\mathrm{S}}^{\mathrm{o}}$ is given by equation 4

$$
\Delta G_{\mathrm{S}}^{0}=\mathrm{R} T \ln V_{\mathrm{R}}^{0}+\mathrm{K}
$$

where $\mathrm{R}$ is the gas constant and $\mathrm{K}$ is the De Boer or Kemball/Rideal constant depending on the chosen reference state (De Boer, 1953; Kemball \& Rideal, 1946). Moreover, $\Delta G_{\mathrm{S}}^{0}$ is related to the energy of adhesion $W_{\mathrm{A}}$ (between probe molecule and solid) by equation 5

$$
\Delta G_{\mathrm{S}}^{0}=\mathrm{N}_{\mathrm{A}} * a^{*} W_{\mathrm{A}}
$$

where $a$ is the cross-sectional area of the adsorbate and $\mathrm{N}_{\mathrm{A}}$ the Avogadro constant. The dispersive contribution of the work of adhesion $W_{\mathrm{A}}$ is obtained following Fowkes, 1964 (equation 6).

$$
W_{\mathrm{A}}=2\left(\gamma_{\mathrm{S}}^{\mathrm{D}} * \gamma_{\mathrm{L}}^{\mathrm{D}}\right)^{1 / 2}
$$




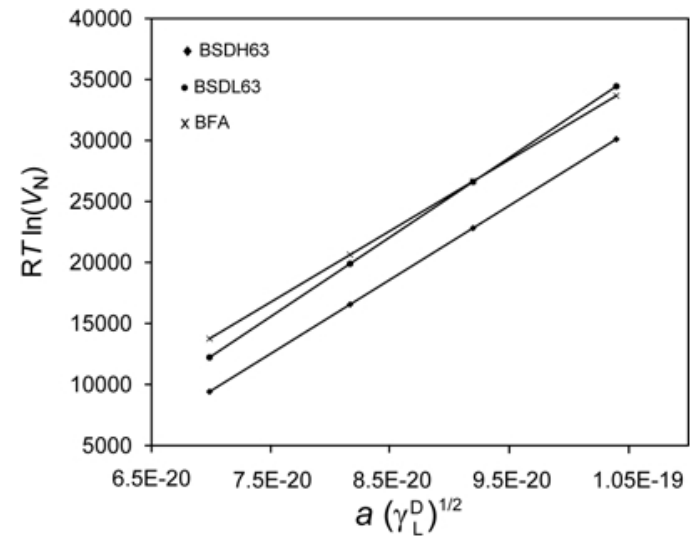

FIG. 1. Energy of adsorption vs. $a\left(\gamma_{\mathrm{L}}^{\mathrm{D}}\right)^{1 / 2}$ for $\mathrm{n}$-alkanes on the bentonite surface at $T=393 \mathrm{~K}$ and $0 \%$ R.H.

where $\gamma_{\mathrm{S}}^{\mathrm{D}}$ and $\gamma_{\mathrm{L}}^{\mathrm{D}}$ are the surface tensions of the adsorbent and adsorbate, respectively. Combining the equations above (equations 4, 5 and 6), equation 7 was obtained.

$$
\mathrm{R} T \ln V_{\mathrm{R}}^{0}=2 \mathrm{~N}_{\mathrm{A}}\left(\gamma_{\mathrm{S}}^{\mathrm{D}}\right)^{1 / 2} \mathrm{a}\left(\gamma_{\mathrm{L}}^{\mathrm{D}}\right)^{1 / 2}+\mathrm{const}
$$

where the dispersive component of the surface tension $\left(\gamma_{\mathrm{S}}^{\mathrm{D}}\right)$ values of the bentonite could be calculated based on the plots of $\mathrm{R} T \ln V_{\mathrm{R}}^{0} v s$. $a$ $\left(\gamma_{\mathrm{L}}^{\mathrm{D}}\right)^{1 / 2}$ (equation 7 ) for the adsorption of $n$-alkane probes, as illustrated in Fig. 1.

For all specimens under investigation, excellent linear correlations (0.997-0.9998) were obtained for the n-alkane series. Table 1 summarizes the bentonite $\gamma_{\mathrm{S}}^{\mathrm{D}}$ values determined.

TABLE 1. Dispersive component of the surface tension $\left(\gamma_{\mathrm{s}}^{\mathrm{D}}\right)$ of the surfaces of bentonite particles.

\begin{tabular}{lccc}
\hline Clay & $\begin{array}{c}T \\
(\mathrm{~K})\end{array}$ & $\begin{array}{c}\text { R.H. } \\
(\%)\end{array}$ & $\begin{array}{c}\gamma_{\mathrm{S}}^{\mathrm{D}} \\
\left(\mathrm{mJ} \mathrm{m}^{-2}\right)\end{array}$ \\
\hline \multirow{3}{*}{ BSDH63 } & 303 & 10 & 191.8 \\
& 303 & 20 & 84.1 \\
& 303 & 30 & 53.6 \\
& 393 & 0 & 261.3 \\
BSDL63 & 373 & 0 & 301.6 \\
& 378 & 0 & 298.6 \\
& 383 & 0 & 296.2 \\
BFA & 388 & 0 & 293.7 \\
& 393 & 0 & 291.3 \\
\hline
\end{tabular}

Bentonite $\gamma_{\mathrm{S}}^{\mathrm{D}}$ values were compared with the corresponding values obtained for different clay types reported by various authors (Morales et al., 1991; Saada, 1995; Hamdi et al., 1999; Price \& Ansari, 2003). The $\gamma_{S}^{D}$ values obtained for the bentonite samples under investigation are greater than those obtained for the other clay types (kaolinite, smectite and illite) (145 to $212 \mathrm{~mJ} \mathrm{~m}^{-2}$ at $398 \mathrm{~K})$ and also for bentonite $\left(155 \mathrm{~mJ} \mathrm{~m}^{-2}\right.$ at 373 K) (Hamdi et al., 1999).

The high values of $\gamma_{\mathrm{S}}^{\mathrm{D}}$ from different clays can result from retention of the alkane probes in structural heterogeneities (nanorugosities) with a consequent increase in the apparent $\gamma_{\mathrm{S}}^{\mathrm{D}}$ values (Rodriguez et al., 1997). The composition, size and distribution, as well as shape of particles, contribute to the different values found for the various clays specimens.

The bentonite size fraction $<0.063 \mathrm{~mm}$ (BSDL63) has the greatest surface energy, with $291.3 \mathrm{~mJ} \mathrm{~m}^{-2}$ at $393 \mathrm{~K}$. This result can be explained by the greater specific surface area and porosity of the BSDL63 fraction as determined by the BET study (see below). Generally, clays with large surface areas are more porous and may retain small probes more strongly, leading to greater surface free-energy results.

It was observed that $\gamma_{\mathrm{S}}^{\mathrm{D}}$ values decrease linearly with temperature (correlation coefficient: 0.998). A similar decrease in $\gamma_{\mathrm{S}}^{\mathrm{D}}$ values with temperature was also obtained in several different materials. However, in previous work (Morales et al., 1991; Hamdi et al., 1999) an increase in $\gamma_{S}^{D}$ values for sepiolite and bentonite with temperature was observed. This can be explained by the water adsorbed on the particle surfaces. If the samples are not well dried, the water adsorbed in the surface material does not permit contact between the material and the probe. To eliminate this problem in this study, the samples were pre-treated for $2 \mathrm{~h}$ at $393 \mathrm{~K}$ to remove all the adsorbed water on the surface. Moreover, in the present work we studied the humidity (R.H.) influence on the surface energy. It was observed that $\gamma_{\mathrm{S}}^{\mathrm{D}}$ decreased sharply as the R.H. increased (Table 1). As the R.H. increases, the surface covering becomes larger and the dispersive interaction drops. Furthermore, after exposing the sample to high R.H. $(50 \%)$, the sample was re-tested at $0 \%$ R.H. and the molecule probe retention time was the same, which implies that no irreversible change (chemisorption) occurred in the sample when it was subjected to high humidity levels. 


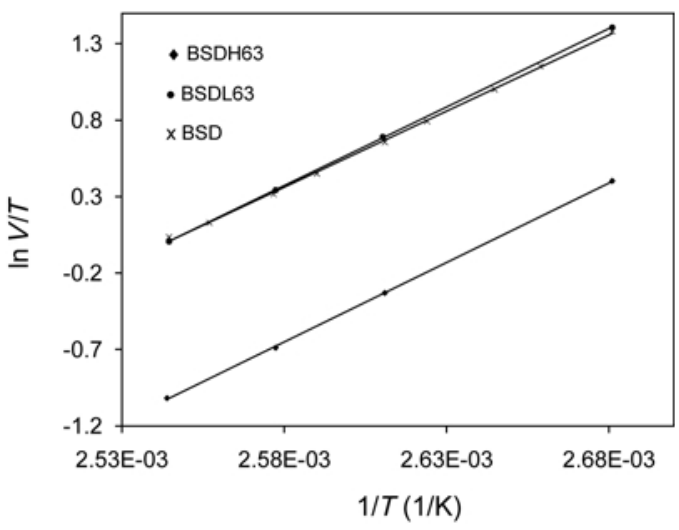

FIG. 2. Heat of sorption plot and linear fits for n-heptane measurement on clays $373-393 \mathrm{~K}$, at

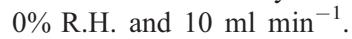

\section{Heat of sorption measurements}

In the infinite dilution region, where the isotherm is linear, $V_{\mathrm{N}}$ should be measured at a range of column temperatures and $\ln \left(V_{\mathrm{N}} / T\right)$ plotted $v s .1 / T$, which yields the heat of sorption $\Delta H_{\mathrm{s}}$ according to Conder \& Young, 1979 (equation 8)

$$
\left(\frac{\partial \ln \left(\frac{V_{\mathrm{N}}}{T}\right)}{\partial\left(\frac{1}{T}\right)}\right)=-\frac{\Delta H_{\mathrm{s}}}{\mathrm{R}}
$$

To determine the enthalpies of sorption $\left(\Delta H_{\mathrm{S}}\right)$ of the n-hexane and polar probes in our clays, the specific retention volume $\left(V_{\mathrm{N}}\right)$ was measured at different temperatures (373 to $393 \mathrm{~K})$ and the retention diagrams $\ln V_{\mathrm{N}}$ vs. $1 / T$ were plotted (Fig. 2). Porto Santo bentonites show similar $\Delta H_{\mathrm{S}}$ of $\sim 80 \mathrm{~kJ} \mathrm{~mol}^{-1}$ at $0 \%$ R.H. (Table 2). By comparing $\Delta H_{\mathrm{S}}$ values to the condensation enthalpy of the probes $\Delta H_{\mathrm{c}}$, it was observed that $\Delta H_{\mathrm{S}}$ is greater than $\Delta H_{\mathrm{C}}$. This implies that the enthalpies of sorption measured are not only due to the heat of condensation of the compounds onto the matrix, but also to physicochemical interactions between probe and samples. $\Delta H_{\mathrm{S}}-\Delta H_{\mathrm{C}}$ was $\sim 40 \mathrm{~kJ} \mathrm{~mol}^{-1}$ for $\mathrm{n}$-hexane. These values correspond to weak energy bonds such as dipole-dipole interactions. This behaviour confirms that the alkanes used are good probe molecules for the determination of 'dispersive' properties such as the surface energy and surface area.

As in the case of surface energy, the values obtained for the heat of sorption in bentonite were slightly greater than those found for kaolinite and illite (49 to $62 \mathrm{~kJ} \mathrm{~mol}^{-1}$; Saada et al., 1995).

The experiment carried out at $10 \%$ R.H. in specimen BSDH63 showed a sharp decrease in the heat of sorption to $28 \mathrm{~kJ} \mathrm{~mol}^{-1}$. As mentioned, the increase in R.H. gave rise to water cluster formation, which disabled the interaction between the alkane probe molecules and the dispersive centres on the surface. This is supported by a comparison of the values obtained for the heat of sorption with the heat of condensation $\left(34 \mathrm{~kJ} \mathrm{~mol}^{-1}\right.$ for heptane). Usually, the heat of condensation is expected to be smaller than the heat of sorption. Moreover, at high R.H. the solid surface is partially covered with water; consequently the heat of sorption will reflect the smaller value of the heat of mixing of heptane/water.

\section{Polar probes sorption studies}

A comprehensive insight into the Lewis acid/base surface interactions can provide better understanding of the influence of the chemical-physical properties of bentonites, as well as their ability to change via chemical modifications, which is of great importance for their applications.

The presence of acid and base active sites on the surfaces increases the possibility of specific intermolecular interactions with solvents and other compounds.

TABLE 2. Surface properties obtained for bentonite particle surfaces.

\begin{tabular}{lccccccc}
\hline Clay & $\mathrm{K}_{\mathrm{a}}$ & $\mathrm{K}_{\mathrm{b}}$ & $\mathrm{K}_{\mathrm{b}} / \mathrm{K}_{\mathrm{a}}$ & $\begin{array}{c}\text { Heterogeneity } \\
\left(\mathrm{kJ} \mathrm{mol}^{-1}\right)\end{array}$ & $\begin{array}{c}\text { Surface area } \\
\left(\mathrm{m}^{2} \mathrm{~g}^{-1}\right)\end{array}$ & $\begin{array}{c}\text { Deemter } \\
\left(\mathrm{cm} \mathrm{s}^{-1}\right)\end{array}$ & $\begin{array}{c}\text { Heat adsorption } \\
\left(\mathrm{kJ} \mathrm{mol}^{-1}\right)\end{array}$ \\
\hline BSDH63 & 0.38 & 1.00 & 2.63 & 14.4 & 78.94 & $9.51 \times 10^{-4}$ & -84.50 \\
BSDL63 & 0.35 & 0.90 & 2.58 & 12.9 & 144.5 & $3.17 \times 10^{-5}$ & -85.86 \\
BFA & 0.20 & 1.10 & 5.50 & 14.8 & 7.59 & $9.12 \times 10^{-4}$ & -82.81
\end{tabular}


The specific free energy of sorption, $\Delta G_{\mathrm{s}}^{0}$, corresponding to the polar probes, is a measure of how easily particle surfaces can polarize the probe and was determined by the difference between the value of the energy of adsorption of a particular polar probe and the corresponding value in the n-alkanes reference line.

Figure 3 shows the specific free energies of sorption for the three samples. BSD samples, in particular BSDL63, show greater $\Delta G_{\mathrm{s}}^{0}$ values than the BFA. The values were significantly greater in the case of dichloromethane, acetone and methanol. This means, in terms of practical applications, that BSDL63 is the best adsorbent for polar probe molecules. The trend for the different probe molecules is the same for all the samples: methanol shows the strongest interaction, while chloroform shows the weakest. Methanol has a hydrophilic and slightly acidic character, whereas chloroform is a hydrophobic weak base.

The strong interaction with methanol, due to cation solvation (Annabi-Bergaya et al., 1979, 1980a,b, 1981), is in agreement with the high hydrophilic character of this bentonite's surface particles. This hydrophilic character of the surface explains the high dependence of surface parameters on the humidity. Attempts to determine retention times for other reference Lewis acid and/or hydrophilic probes were unsuccessful due to a very strong adsorption of these probes onto the stationary phases.

These results show that these kinds of probes interact strongly with the stationary phases, and thus indicate predominant hydrophilic-basic sites on the surfaces of these materials.
The observation of $\Delta G^{0}$ results for benzene, a Lewis base through $\pi$-interaction, or to acetone, a weak base, indicates an apparent loss of basicity when the wet sieving was carried out.

According to Gutman (1978), the enthalpy $\left(\Delta H_{\mathrm{S}}\right)$ is related to the acid-base numbers by equation 9 :

$$
-\Delta H_{\mathrm{S}}=\mathrm{K}_{\mathrm{a}} \Delta \mathrm{DN}+\mathrm{K}_{\mathrm{b}} \Delta \mathrm{AN}
$$

where $\mathrm{DN}$ and $\mathrm{AN}$ are the donor and acceptor values of the polar probes, respectively. The constants $\mathrm{K}_{\mathrm{a}}$ and $\mathrm{K}_{\mathrm{b}}$ characterize the ability of the solid sample to accept or to donate electrons.

To obtain $\mathrm{K}_{\mathrm{a}}$ and $\mathrm{K}_{\mathrm{b}}, \Delta H_{\mathrm{S}}$ must be calculated for probe molecules (Mukhopadhyay \& Schreiber, 1995). Thus, the parameters can be determined by linearizing equation 9:

$$
-\frac{\Delta H_{\mathrm{s}}}{\mathrm{AN}}=\frac{\mathrm{DN}}{\mathrm{AN}} \mathrm{K}_{\mathrm{a}}+\mathrm{K}_{\mathrm{b}}
$$

The overall acid/base character of samples can be evaluated from the ratio of $\mathrm{K}_{b} / \mathrm{K}_{\mathrm{a}}$. At $\mathrm{K}_{\mathrm{b}} / \mathrm{K}_{\mathrm{a}}>1$, the surface is considered to be basic, while for $\mathrm{K}_{\mathrm{b}} / \mathrm{K}_{\mathrm{a}}$ $<1$, the surface is acidic.

Consequently, as seen from the data in Table 2, the surfaces of specimens exhibited high Lewis basic character, with the ratio of $\mathrm{K}_{\mathrm{b}} / \mathrm{K}_{\mathrm{a}}$ between 2.58 and 5.50. Furthermore, these results show that the BFA has a higher basic character $\left(\mathrm{K}_{\mathrm{b}} / \mathrm{K}_{\mathrm{a}}=5.50\right)$.

The conclusion is in agreement with the results obtained for the $\mathrm{pH}$ measured by water dissolution, and explains the application of the clays as an antiacid product for gastrointestinal problems by the native population.

Different studies on clays from other origins are known but, unlike the Porto Santo clays, they have

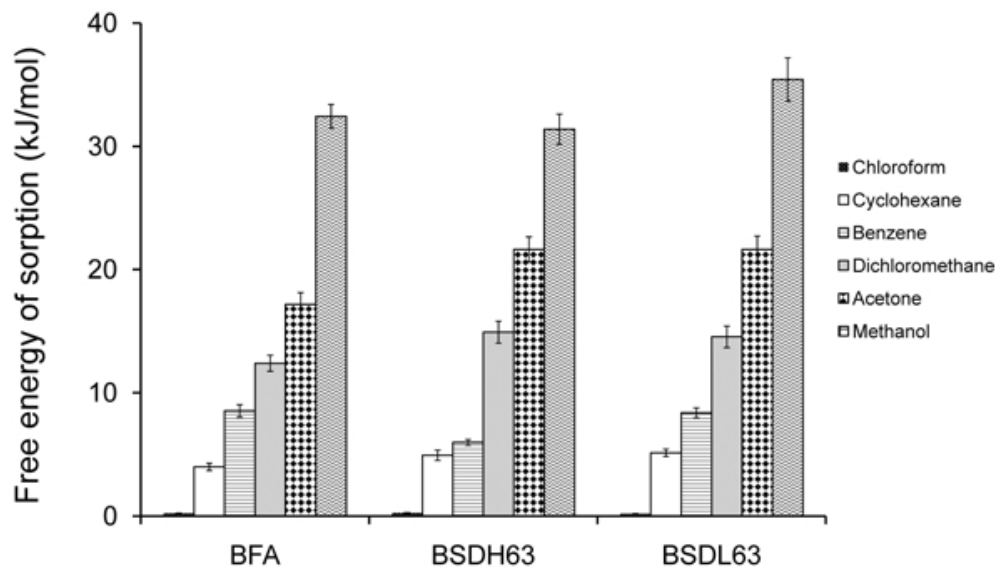

FIG. 3. Specific free energy of interaction for the three bentonites analysed at $393 \mathrm{~K}$. 
strong acidic properties (Lahav et al., 1978; Vaughan et al., 1979; Occelli \& Tindwa, 1983; Brindley \& Yamanaka, 1979; Morales et al., 1991).

\section{Isotherm measurements}

For the calculation of the sorption isotherm the partial pressures $p$ can be obtained from the peak heights $h$ by equation 11:

$$
p=h^{*} V_{\text {loop }} * p_{\text {sat }} * p_{\mathrm{o}} * 273 /\left(F^{*} A^{*} \mathrm{~T}_{\text {loop }}\right)
$$

where $V_{\text {loop }}$ is the volume of the probe molecule injection loop, $p_{\text {sat }}$ is the vapour pressure inside the loop and $A$ the area under the peak. The retention volume in the peak maximum for every injection is used to calculate the values for $V_{\mathrm{N}} / \mathrm{R} T$. A plot of $V_{\mathrm{N}} / \mathrm{R} T$ vs. $p$ represents the first derivative of the sorption isotherm (Cremer \& Huber, 1962).

Figure 4 shows the pulse isotherms for a multiple injection experiment with n-hexane on BSDL63 at $393 \mathrm{~K}$. The isotherm curve (Fig. 5) was made at the relative pressures $0<p / p_{\mathrm{o}}<0.01$, where only the micropores were filled (Brunauer et al., 1940; Schneider, 1995; Önal \& Sarıkaya, 2009). This physisorption curve explains the tailing in the chromatogram (Fig. 4).

The peak maximum isotherm has been used to calculate surface areas according to BET (Brunauer et al., 1938). The BET model is given by equation 12

$$
\frac{n}{n_{\mathrm{m}}}=\frac{\mathrm{C} x}{(1-x)[1+(\mathrm{C}-1) x]}
$$

In this equation $n$ is the amount sorbed, $n_{\mathrm{m}}$ is the monolayer capacity, $\mathrm{C}$ is a constant (related to the

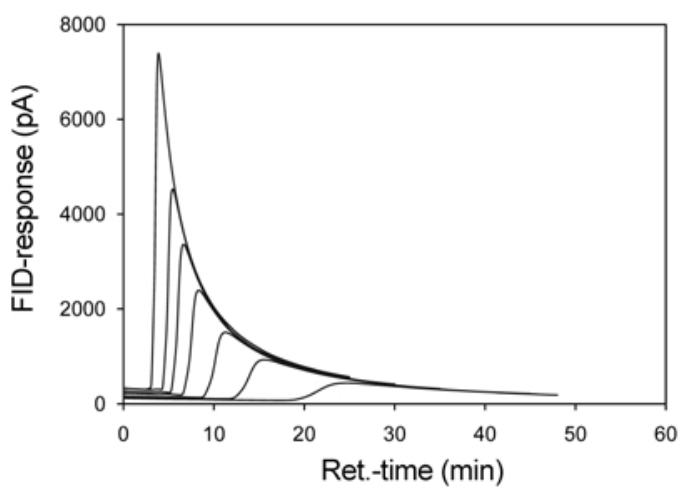

FIG. 4. Pulses of different concentration of n-hexane on BSDL63 at $303 \mathrm{~K}$. heat of sorption) and $x$ is the reduced pressure $\left(p / p_{\mathrm{o}}\right)$. A plot of $x /[n(1-x)]$ vs. $x$ usually gives a straight line from which the monolayer capacity $n_{\mathrm{m}}$ can be calculated.

If the cross-sectional area $a_{\mathrm{m}}$ of the probe molecule is known, the BET surface area $A_{\mathrm{BET}}$ can be readily calculated using the Avogadro constant $\mathrm{N}_{\mathrm{L}}$ (equation 13).

$$
A_{\mathrm{BET}}=n_{\mathrm{m}} * a_{\mathrm{m}} * \mathrm{~N}_{\mathrm{L}}
$$

The hexane monolayer capacities found were $0.047 \mathrm{mmol} \mathrm{g}^{-1}$ and $0.025 \mathrm{mmol} \mathrm{g}^{-1}$ for BSDL63 and BSDH63 respectively. In the case of BFA, a value of $0.025 \mathrm{mmol} \mathrm{g}^{-1}$ was observed.

The bentonite surface area values for BSDL63 and BSDH63 were found to be 144 and $79 \mathrm{~m}^{2} \mathrm{~g}^{-1}$ respectively, which correlates with particle size. A similar value was found for the BSDL63 surface area measured by nitrogen adsorption $\left(105 \mathrm{~m}^{2} \mathrm{~g}^{-1}\right)$. These results are of the same order as those found by Carvalho et al., $1996\left(142 \mathrm{~m}^{2} \mathrm{~g}^{-1}\right)$ for the $<0.045 \mathrm{~mm}$ Porto Santo clay fraction by $\mathrm{N}_{2}$ adsorption measurements.

If the surfaces are heterogeneous, sites of different adsorption energy can exist. Starting a measurement at infinite dilution, initially only the greatest energy sites will interact. On increasing the partial pressure, more and more active sites will be involved in the interaction. For this reason, measurements at various concentrations (isotherms) provide information regarding the surface heterogeneity. The heterogeneity profile constitutes an energy 'map' of the material surface. Such information permits a prediction of the product's properties.

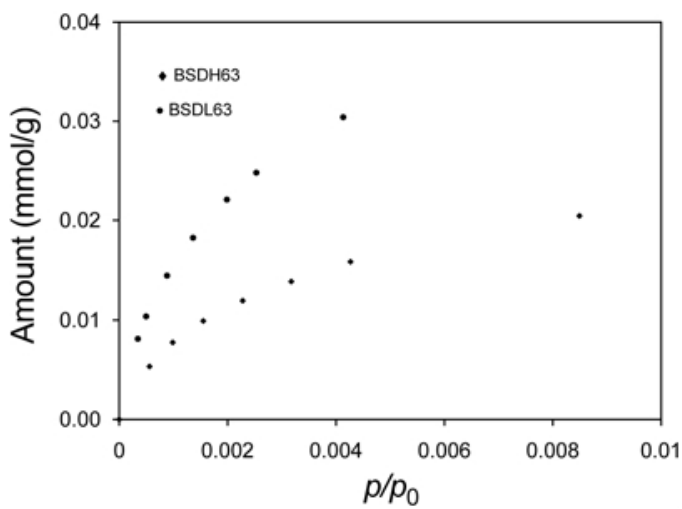

FIG. 5. Sorption isotherms for hexane on the bentonite at $303 \mathrm{~K}$ and $10 \mathrm{ml} \mathrm{min}^{-1}$ carrier gas flow rate. 
In order to obtain the adsorption potential distribution function the partial pressures are converted into the adsorption potential A according to equation 14 :

$$
\mathrm{A}=\mathrm{R} T \ln \left(\frac{p^{o}}{p}\right)
$$

where $p$ is the partial pressure, $p^{\mathrm{o}}$ the saturation pressure, $\mathrm{R}$ the gas constant and $T$ the column temperature. The distribution parameter $\Phi$ represents the first derivative of the sorbed amount $n$ with the adsorption potential $A$ (equation 15):

$$
\Phi=-\frac{\mathrm{d} n}{\mathrm{~d} A}
$$

Surface heterogeneity profiles were determined in this study by the variation of the concentration of $n$ hexane and cyclohexane as probe molecules. It can be seen from Fig. 6 that the bentonite clays present similar profiles, with one large dominant peak. The intensity of the peak decreases and shifts slightly towards lower energy with the particle size decrease. The peak is centred around $14 \mathrm{~kJ} \mathrm{~mol}^{-1}$ for BFA and BSDH63, while the maximum of the distribution curve of BSDL63 is located at a lower adsorption potential $\left(13 \mathrm{~kJ} \mathrm{~mol}^{-1}\right)$. The adsorption peak in the high-energy region can be due to the presence of micropores. The large peaks observed, particularly in BSD samples, can mean a wide distribution of various surface sites of different energy levels. As the nature of the surface heterogeneity (gas-solid interactions) depends on the adsorbate molecule, the surface heterogeneity profile of BSDH63 was determined with cyclohexane (figure not shown). The energy profile is

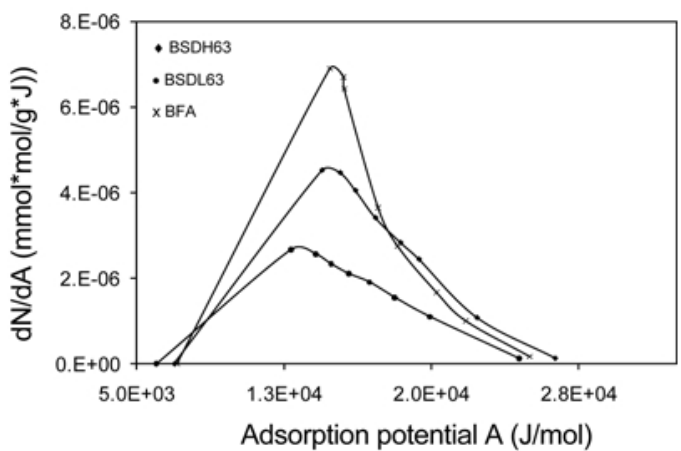

FIG. 6. Heterogeneity profiles of bentonite at $303 \mathrm{~K}$ for n-hexane. similar to the hexane profile with only one significant large maximum around $13 \mathrm{~kJ} \mathrm{~mol}^{-1}$.

Another important surface parameter in manufacturing and storage stability is the permeability or the diffusion coefficient. There are several approaches described in the literature for these determinations. A simple and fast determination of the diffusion coefficient uses the van Deemter approach (van Deemter et al., 1965). For this calculation, the retention time of the probe molecule is measured at different carrier gas flow rates. The retention time is then transformed into the theoretical plate height $H$, which is plotted $v s$. the linear flow rate $u$ (equation 16)

$$
H=\mathrm{A}+\frac{\mathrm{B}}{u}+\mathrm{C} * u
$$

$\mathrm{A}$ and $\mathrm{B}$ in equation 16 are constants representing the eddy diffusion and the molecular diffusion in the gas phase, respectively (van Deemter et al., 1965). The constant $\mathrm{C}$ is a factor relating to nonequilibrium behaviour. By knowing the column geometry, the linear flow rate $u$ can be readily calculated from the experimental flow rate. $H$ is directly related to the peak width $b$ (equation 17)

$$
H=\frac{L}{8 \ln 2}\left(\frac{b}{t_{\mathrm{R}}}\right)^{2}
$$

In this equation, $L$ represents the column length and $t_{\mathrm{R}}$ the gross retention time.

Assuming that the mass transfer resistance is due to the diffusion into the stationary phase (adsorbent), the diffusion coefficient $D_{\mathrm{P}}$ can be calculated from the constant $\mathrm{C}$ (equation 18):

$$
\mathrm{C}=\left(\frac{16}{\Pi}\right)\left(\frac{d^{2}}{D_{\mathrm{p}}}\right)\left[\frac{k}{(1+k)}\right]
$$

Here $d$ is the average particle size or film thickness respectively and $k$ is the partition coefficient which is defined as follows, where $t_{0}$ is the dead time:

$$
k=\frac{\left(t_{\mathrm{R}}-t_{0}\right)}{t_{0}}
$$

Figure 7 shows the experimental curves for the dependence of the retention volume from the flow rate of the $n$-hexane sorption on bentonite. The diffusion coefficient $\left(D_{\mathrm{p}}\right)$ for $\mathrm{n}$-hexane yields $3.17 \times 10^{-5}$ and $9.51 \times 10^{-4} \mathrm{~cm}^{2} \mathrm{~s}^{-1}$ for BSDL63 


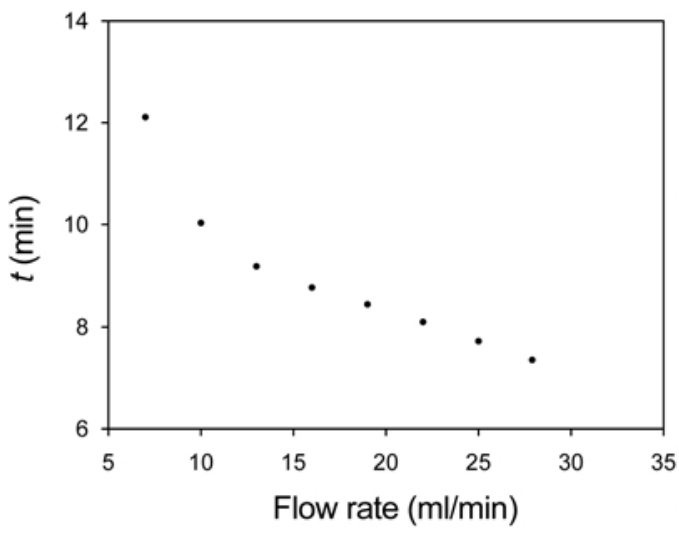

FIG. 7. n-Hexane retention volume vs. flow rate for BSDL63 at $303 \mathrm{~K}$.

and BSDH63 respectively (Table 2). In the case of BFA, a value of $9.12 \times 10^{-4} \mathrm{~cm}^{2} \mathrm{~s}^{-1}$ was found. The great difference in the diffusion coefficient was clearly due to the particle size, and consequently its tendency to particle aggregation - an increase in particle size or in size heterogeneity decreases the diffusion coefficient. These results are in agreement with Kapolos et al. (2005) who showed that the porous size of the solid is a critical parameter in the diffusion of gases into porous solids. These authors found alumina values of order of magnitude $10^{-3} \mathrm{~cm}^{2} \mathrm{~s}^{-1}$.

\section{CONCLUSIONS}

In the present work the surface properties of the clays used in dermopharmacy and dermocosmetics have been characterized exhaustively by IGC at infinite dilution. This study clearly demonstrates that the bentonite clays from Porto Santo Island, Madeira archipelago, exhibit very large dispersive surface energies and a predominantly basic character. Also, from results obtained, other important conclusions can be drawn: (1) under the same conditions the clay from Fonte da Areia has less dispersive surface energy and the higher basic character; (2) the finer fraction has the smaller value of dispersive surface energy; (3) the heat of adsorption values are very similar for all the bentonites studied; (4) the enthalpies of adsorption of alkane probes and the dispersive component of surface energy are strongly influenced by humidity, decreasing with increasing humidity. Based on this study we can conclude that the finer fraction
$(<0.063 \mathrm{~mm})$ is better for applications in dermopharmacy and dermocosmetics due to its superior adsorptive properties.

In addition, the results of the research carried out show that IGC is a fast and accurate method for the characterization of the surface properties of clay minerals. The study could be significant in terms of the value of the materials for dermopharmacy and dermocosmetics applications of the Porto Santo bentonites.

\section{ACKNOWLEDGMENTS}

The Portuguese Foundation for Science and Technology (FCT) has sponsored this work carried out at the Research Centres CEM and GeoBioTec.

\section{REFERENCES}

Annabi-Bergaya F., Cruz M.I., Gatineau L. \& Fripiat J.J. (1979) Adsorption of alcohols by smectites: I. Distinction between internal and external surfaces. Clay Minerals, 14, 249-258.

Annabi-Bergaya F., Cruz M.I., Gatineau L. \& Fripiat J.J. (1980a) Adsorption of alcohols by smectites: II. Role of the exchangeable cations. Clay Minerals, 15, $219-223$.

Annabi-Bergaya F., Cruz M.I., Gatineau L. \& Fripiat J.J. (1980b) Adsorption of alcohols by smectites: III. Nature of the bonds. Clay Minerals, 15, 225-237.

Annabi-Bergaya F., Cruz M.I., Gatineau L. \& Fripiat J.J. (1981) Adsorption of alcohols by smectites: IV Models. Clay Minerals, 16, 115-122.

Bandosz T.J., Jagiello J., Amankwah K.A.G. \& Schwarz J.A. (1992) Chemical and structural properties of clay minerals modified by inorganic and organic material. Clay Minerals, 27, 435-444.

Boutboul A., Lenfant F., Giampaoli P., Feigenbaum A. \& Ducret V. (2002) Use of inverse gas chromatography to determine thermodynamic parameters of aroma-starch interactions. Journal of Chromatography A, 969, 9-16.

Brindley G.W. \& Yamanaka S. (1979) A study of hydroxy-chromium montmorillonites and the form of the hydroxy-chromium polymers. American Mineralogist, 64, 830-835.

Brunauer S., Emmett P.H. \& Teller E. (1938) Adsorption of gases in multimolecular layers. Journal of the American Chemical Society, 60, 308-319.

Brunauer S., Deming L.S., Deming D.M. \& Teller E. (1940) On the theory of the van der Waals adsorption on gases. Journal of the American Chemical Society, 62, $1723-1732$.

Carvalho M.B., Pires J. \& Carvalho A.P. (1996) 
Characterization of clays and aluminium pillared clays by adsorption of probe molecules. Microporous Materials, 6, 65-77.

Conder J.R. \& Young C.L. (1979) Physicochemical Measurement by Gas Chromatography, Wiley, New York.

Cremer E. \& Huber H. (1962) Measurement of adsorption isotherms by means of high temperature elution gas chromatography. International Symposium on Capillary Chromatography, 3, 169-182.

De Boer J.H. (1953) The Dynamic Character of Chemisorptions, 2nd edition. Clarendon Press, Oxford, UK.

Elizalde-González M.P. \& Ruíz-Palma R. (1999) Gas chromatographic characterization of the adsorption properties of the natural adsorbent CACMM2. Journal of Chromatography A, 845, 373-379.

Fowkes F.N. (1964) Attractive forces at interfaces. Industrial \& Engineering Chemistry, 56 (12), 40-52.

Gomes C.S.F. (2005) Mineral-based products for applications in balneotherapy: An interesting field for research, development and innovation. XIX Reunión de la Sociedad Española de Arcillas, Salamanca, España, 89-90.

Gomes C.F.G. \& Silva J.B.P., editors (2001) Beach sand and bentonite of Porto Santo island: Potentialities for applications in Geomedicine. O Liberal, Câmara de Lobos, R.A.M., Portugal, 60 pp.

Gomes C.F.G. \& Silva J.B.P. (2006a) Products based on clay, mud, and sand with interest for balneotherapy. Clay Science, 12, 228-232.

Gomes C.S.F. \& Silva J.B.P. (2006b) Minerals and Human Health: Benefits and Risks. Published by the authors, Porto, Portugal, $185 \mathrm{pp}$.

Gomes C.S.F. \& Silva J.B.P. (2007) Minerals and clay minerals in medical geology. Applied Clay Science, 36, 4-21.

Gutmann V. (1978) The Donor Acceptor Approach to Molecular Interactions. Plenum Press, New York.

Hamdi B., Kessaissia Z., Donnet J.B. \& Wang T.K. (1999) Variation of surface energy of a bentonite by chemical and thermal treatments. Annales de Chimie Science des Materiaux, 24, 63-73.

Kapolos J., Bakaoukas N., Koliadima A. \& Karaiskakis G. (2005) Measurements of diffusion coefficients in porous solids by inverse gas chromatography. Journal of Phase Equilibria and Diffusion, 26, 477-481.

Kemball C. \& Rideal E.K. (1946) The adsorption of vapours on mercury. I. Non-polar substances. Proceedings of the Royal Society of London. Series A, 187, 53-73.

Lahav M., Shani U. \& Shabtai J. (1978) Cross-linked smectites; I, Synthesis and properties of hydroxyaluminum-montmorillonite. Clays and Clay Minerals, 26, 107-115.

Lloyd D.R., Ward T.C. \& Schreiber H.P. (1989) Inverse
Gas Chromatography, ACS Symposium Series, 391, Washington.

Morales E., Dabrio M.V., Herrero C.R. \& Acosta J.L. (1991) Acid/base characterization of sepiolite by inverse gas chromatography. Chromatografia, 31, $357-361$.

Mukhopadhyay P. \& Schreiber H.P. (1995) Aspects of acid-base interactions and use of inverse gas chromatography. Colloid and Surfaces A, 100, 47-71.

Occelli M.L. \& Tindwa P.M. (1983) Physicochemical properties of montmorillonite interlayered with cationic oxyaluminium pillars. Clays and Clay Minerals, 31, 22-28.

Önal M. \& Sarıkaya Y. (2009) Some physicochemical properties of a clay containing smectite and palygorskite. Applied Clay Science, 44, 161-165.

Papirer E., Brendle E., Ozil F. \& Balard H. (1999) Comparison of the surface properties of graphite, carbon black and fullerene samples measured by inverse gas chromatography. Carbon, 37, 1265-1274.

Price G.J. \& Ansari D.M. (2003) An inverse gas chromatography study of calcination and surface modification of kaolinite clays. Physical Chemistry Chemical Physics, 5, 5552-5557.

Saada A., Papirer E., Balard H. \& Siffert B. (1995) Determination of the surface properties of illites and kaolinites by inverse gas chromatography, Journal of Colloid and Interface Science, 175, 212-218.

Schneider P. (1995) Adsorption isotherms of microporous-mesoporous solids revisited, Applied Catalysis A: General, 129, 157-165

Silva J.B.P. (2003) Areia de Praia da ilha do Porto Santo: Geologia, génese, dinâmica e propriedades justificativas do seu interesse medicinal: Madeira rochas. Divulgações Científicas e Culturais, Funchal, Madeira, 344 pp.

Rodriguez M., Rubio J., Rubio F., Liso M. \& Oteo J. (1997) Application of inverse gas chromatography to the study of the surface properties of slates. Clays and Clay Minerals, 45, 670-680.

van Deemter J., Zuiderweg F.J. \& Klinkenberg A. (1965) Longitudinal diffusion and resistance to mass transfer as causes of nonideality in chromatography. Chemical Engineering Science, 5, 271-289.

Vaughan D.E.W., Lussier R.G. \& Magee J.S. (1979) Pillared inter-layered clay materials useful as catalysts and sorbents. U.S. Patent 4,176,090, Nov. 27, 7 pp.

Vega A., Díez F.V., Hurtado P. \& Coca J. (2002) Surface heterogeneity and surface area from linear inverse gas chromatography: Application to glass fibers. Journal of Chromatography A, 962, 153-165.

Xie J., Bousmina M., Xu G. \& Kaliaguine S. (1998) Inverse gas chromatography studies of alkali cation exchanged X-zeolites. Journal of Molecular Catalysis A, 135, 187-197. 